\title{
Endolymphatic Sac Tumor Presenting as an External Ear Canal Mass: A Case Report
}

\author{
Charnsiri Segsarnviriya ${ }^{1 *}$, Paloch Hongtongdang ${ }^{1}$, Rutti Chumthong ${ }^{1}$ and Kantang Satayasoontorn ${ }^{2}$ \\ ${ }^{1}$ Department of Otolaryngology, Phramongkutklao Hospital, Thailand \\ ${ }^{2}$ Department of Anatomical Pathology, Army Institute of Pathology, Thailand
}

*Corresponding author: Charnsiri Segsarnviriya, Department of Otolaryngology, Phramongkutklao Hospital ,315 Rajvithi road, Thung Phayathai, Ratchathewi, Bangkok, Thailand

\section{ARTICLE INFO}

Received: 幽 October 06, 2020

Published: 慧 October 14, 2020

Citation: Charnsiri Segsarnviriya, Paloch Hongtongdang, Rutti Chumthong, Kantang Satayasoontorn. Endolymphatic Sac Tumor Presenting as an External Ear Canal Mass: A Case Report. Biomed J Sci \& Tech Res 31(2)-2020. BJSTR. MS.ID.005060.

Abbreviations: ELST: Endolymphatic Sac Tumor; APMET: Aggressive Papillary Middle Ear Tumor; VHL: von HippelLindau; CT: Computed Tomography

\section{ABSTRACT}

Background: Endolymphatic sac tumor is a rare, aggressive, locally destructive lesion of the skull base that may be sporadic or associated with von Hippel-Lindau disease. It commonly presents as a bluish mass behind an intact tympanic membrane. This report describes a rare case of endolymphatic sac tumor presenting as a mass in the external ear canal.

Case: A 57-year-old female patient presented with a history of progressive unilateral hearing loss and recurrent otorrhea in the right ear for 4 months. Physical examination revealed a mass bulging from the posterior external ear canal. Computed tomography showed an enhancing soft-tissue density lesion in the right external ear canal with minimal bony erosion, including a fluid-filled right mastoid air cell and middle ear cavity. Surgical removal was performed, and the final pathologic results were consistent with aggressive papillary middle ear tumor.

Discussion: Endolymphatic sac tumors originate from the endolymphatic epithelium and are characterized by a locally aggressive papillary growth pattern with bone destruction. The presentation is variable, but histological examination and immunohistochemical staining will aid in the diagnosis. Surgical removal is the treatment of choice.

Keywords: Endolymphatic Sac Tumor; Aggressive Papillary Middle Ear Tumor; Heffner Tumor; Von Hippel-Lindau Disease

\section{Introduction}

Endolymphatic sac tumor (ELST) is a rare lesion of the skull base, the origin of which has recently been ascertained. Although most adenomatous tumors of the temporal bone are benign lesions of the mucosa of the middle ear, aggressive, locally destructive tumors have been reported. In 1988, Gaffey, et al.[1] reported 10 cases of an aggressive papillary middle ear tumor (APMET) characterized by a locally aggressive papillary growth pattern, bone destruction, and frequent endolymphatic sac invasion, which was established as an entity separate from middle ear adenoma. In 1989, Heffner [2] reported 20 cases of a tumor identical to that reported by Gaffey, et al. and proposed an endolymphatic sac origin. The origin of APMET in the endolymphatic sac was based on histological similarity between the tumor and normal endolymphatic sac epithelium. According to the World Health Organization tumor classification (2005), ELST is synonymous with Heffner tumor and APMET [3].

The endolymphatic sac is derived from neuroectoderm and is located subjacent to the posteromedial surface of the temporal bone. This anatomic location explains the potential extension of the tumor. At the early stage, the tumor is located within the endolymphatic sac. At the later stage, it destroys much of the petrous bone, including the middle ear, and extends to the posterior fossa, reaching into the cerebellopontine angle. Despite the controversy about the origin of APMET, current evidence suggests that it is ELST with extension to the middle ear $[4,5]$. ELSTs are known to occur 
more frequently in patients with von Hippel-Lindau (VHL) disease, but the presence of VHL disease is not required for the diagnosis, because sporadic occurrence is common. Patients with VHL disease are more likely to have bilateral ELSTs [6-10]. Here we report a rare case of APMET, with clinical, radiological, histological, and immunohistological findings.

\section{Case Report}

A 57-year-old female patient presented with a history of progressive unilateral hearing loss and recurrent otorrhea in the right ear for 4 months. On examination, a smooth, pinkish mass bulging from the posterior external ear canal was seen in the right ear. The right tympanic membrane could not be evaluated due to mass occlusion. Examination showed that the left ear was intact.
The audiogram showed severe mixed hearing loss in the right ear. Computed tomography (CT) showed an enhancing soft-tissue density lesion in the right external ear canal, with minimal bony erosion, including a fluid-filled right mastoid air cell and middle ear cavity without intracranial extension (Figure 1). Magnetic resonance imaging was offered to the patient as a valuable tool for distinguishing the disease preoperatively, but it was not performed due to the patient's claustrophobia. Tissue biopsy was performed by the punch biopsy technique with the patient under local anesthesia in the outpatient clinic. Pathological examination revealed keratinizing squamous epithelium with hyperkeratosis and prominent stratum granulosum. The preoperative diagnosis was cholesteatoma with external ear involvement.

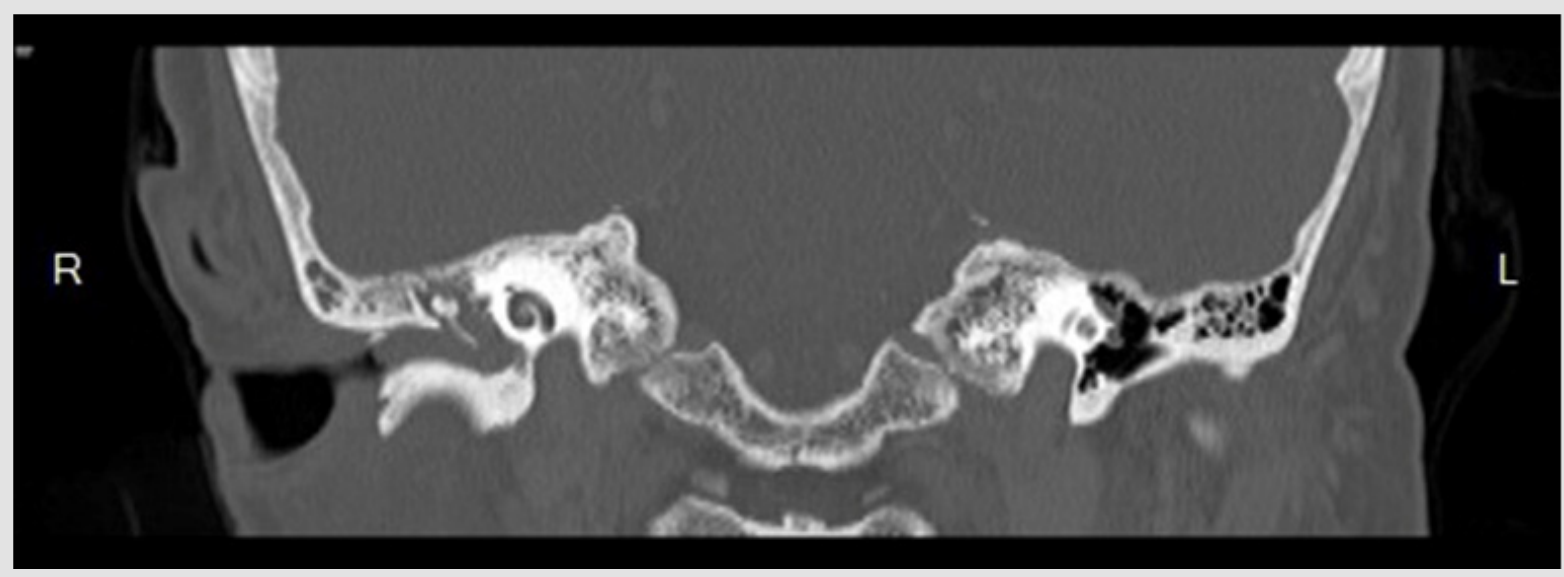

Figure 1: Coronal computed tomography $(\mathrm{CT})$ of bone window showing a soft-tissue density lesion in the right external ear canal with minimal bony erosion.

The patient underwent modified radical mastoidectomy. The surgical findings revealed a pinkish mass that totally occupied the right middle ear cavity (center of mass) with filling into the external ear canal and a small extension into the anterior epitympanum and down to the eustachian tube without endolymphatic sac involvement. The right tympanic membrane, malleus, and incus could not be identified. The mass was meticulously removed with Micro Pick and Micro Crocodile forceps, leaving the right stapes and facial nerve intact. There were no immediate postoperative complications. After postoperative recovery, the patient was discharged on the second day.Pathological examination revealed an aggressive papillary tumor of the middle ear with focal squamous metaplasia. Microscopic examination revealed a papillary glandular pattern with complex interdigitating papillae lying loosely. The papillae were lined by low cuboidal-to-columnar epithelial cells with uniform nuclei, eosinophilic cytoplasm, and distinct cell borders (Figure 2).

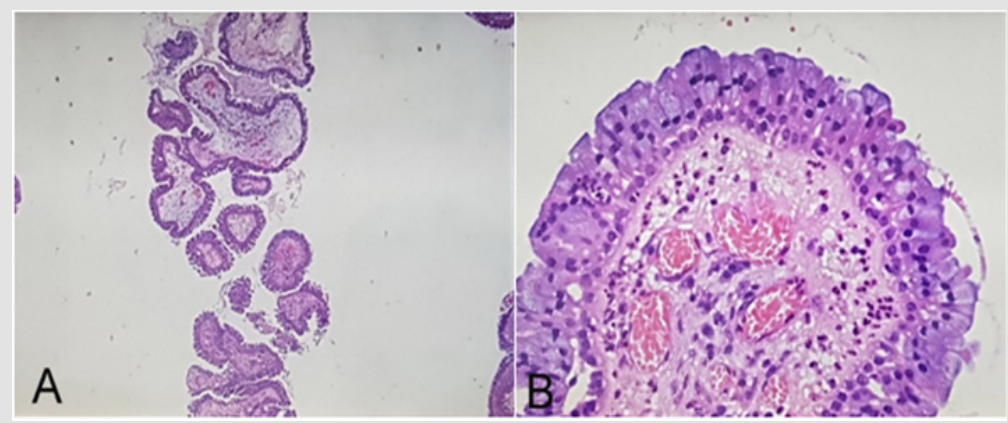

Figure 2: The papillary and glandular structures were lined by a single layer of flattened cuboidal-to-columnar cells with eosinophilic cytoplasm. 
Immunohistochemical tests were positive for epithelial membrane antigen, S100, and AE1/AE3 and negative for thyroid transcription factor 1 , chromogranin, and synaptophysin. At followup, the patient reported improvement in right-sided hearing loss. Microscopic examination revealed normal mucosa of the middle ear and mastoid cavity without tumor recurrence. The postoperative audiogram showed minimal improvement of hearing in the right ear (moderately severe mixed hearing loss). Follow-up examinations were performed every 2 weeks to evaluate the right middle ear and mastoid cavity. Postoperative CT at 6 months found no evidence of tumor recurrence. Of note, no abnormalities were visualized in the endolymphatic sac region. Annual CT was planned as a surveillance tool.

\section{Discussion}

ELSTs are rare, locally aggressive papillary tumors of the petrous bone, which may be sporadic or associated with VHL disease [11], an autosomal dominant disorder. These tumors tend to be bilateral when associated with VHL disease, but they can occur rarely in individuals who do not have mutations or deletions of the VHL gene [8]. Their origin is controversial, but, as the name suggests, they are thought to arise from the endolymphatic sac. Other possible sites of origin include the epithelia of the middle ear and the mastoid air cells [12]. ELSTs were grouped with adenomatous tumors of the middle ear until 1984, when Hassard and colleagues described an extradural papillary lesion that was adherent to the endolymphatic sac [13]. In 1989, Heffner reviewed the light and electron microscopic and immunohistochemical features of 20 papillarycystic tumors of the petrous bone and concluded that they were low-grade adenocarcinomas likely of endolymphatic sac origin [2]. Although these tumors do not typically metastasize, a recent case report by Bambakidis, et al. showed that they can metastasize to distant sites [14].

The tumor affects adults of both sexes from 17 to 71 years of age. The clinical prodrome is prolonged. The most common symptoms are hearing loss, otalgia, tinnitus, vertigo, and facial weakness [15]. Examination typically reveals a red or blue tumor just behind the tympanic membrane. Our patient presented with an unusual case of a mass bulging from the external ear canal. The patient had no symptoms or family history of VHL disease. In most previously reported cases, there was invasion of a portion of the petrous temporal bone, shown as a bony lytic lesion by CT. ELST can be characterized by the stage of growth of the tumor. Initially, ELST involves the adjacent dura and endolymphatic duct, from which the lesion extends to the vestibule, semicircular canals, mastoid, and middle ear cavity. When the tumor extends into the middle ear, it may appear as a bluish or pinkish mass through an intact tympanic membrane. Further growth results in complete replacement of the mastoid and petrous pyramid by tumor.

Finally, invasion of the posterior external ear can occur. In our patient, the tumor growth did not display a typical pattern, because the mass occupied only the middle ear and mastoid cavity. Finally, we hypothesized that the tumor may have originated from the epithelium of the middle ear.Histological examination and immunohistochemical stains could help us to distinguish the disease from other papillary neoplasms of the temporal bone, such as metastatic papillary carcinoma and neuroendocrine tumor of the middle ear.Although these tumors are histologically benign with rare mitotic figures, they are locally aggressive neoplasms, and hence surgical removal is the treatment of choice, although complete resection may not be possible [14]. Patients may require further surgery to resect recurrent disease, and therefore follow-up imaging has an important role in tumor surveillance. Radiotherapy has been used for inoperable tumors, but its use is controversial [15].

To the best of our knowledge, ELST located behind the tympanic membrane has not previously been described. In our patient, the tumor was located in the posterior external ear canal with lytic lesion and chronic mastoiditis on CT. The differential diagnosis includes cholesteatoma, squamous cell carcinoma, and necrotizing otitis externa, but microscopic examination and immunohistochemical staining will help to distinguish these diseases.

\section{Conclusion}

ELST is a rare skull base tumor originating from the endolymphatic epithelium within the vestibular aqueduct, which is characterized by a locally aggressive papillary growth pattern with bone destruction. The presentation is variable, but histological examination and immunohistochemical staining will help to diagnosis the disease. Surgical removal is the treatment of choice.

\section{Conflicts of Interest}

The author declares that I have no conflicts of interest.

\section{References}

1. Gaffey MJ, Mills SE, Fechner RE, Intemann SR, Wick MR (1988) Aggressive papillary middle ear tumor. A clinicopathologic entity distinct from middle-ear adenoma. Am J Surg Pathol 12: 790-797.

2. Heffner DK (1989) Low-grade adenocarcinoma of probable endolymphatic sac origin A clinicopathologic study of 20 cases. Cancer 64: 2292-2302.

3. Michaels L, Beale T, Sandison A (2005) Endolymphatic sac tumour. In: Barnes L, Eveson JW, Reichart P, et al. (Eds.)., World Health Organization classifications of tumors pathology \& genetics head and neck tumor book. Lyon, IARC Press, France, pp: 355-356.

4. Megerian CA, Mc Kenna MJ, Nuss RC, Anthony J Maniglia, Robert G Ojemann, et al. (1995) Endolymphatic sac tumors: histopathologic confirmation, clinical characterization, and implication in von HippelLindau disease. Laryngoscope 105: 801-808.

5. Poe DS, Tarlov EC, Thomas CB, Kveton JF (1993) Aggressive papillary tumor of temporal bone. Otolaryngol. Head Neck Surg 108: 80-86.

6. Horiguchi H, Sano T, Toi H, Kageji T, Hirokawa M, et al. (2001) Endolymphatic sac tumor associated with a von Hippel-Lindau disease patient: an immunohistochemical study. Mod Pathol 14: 727-732.

7. Kawahara K, Kume H, Ueki K, Mishima K, Sasaki T, et al. (1999) VHL gene inactivation in an endolymphatic sac tumor associated with von HippelLindau disease. Neurology 53: 208-210. 
8. Manski TJ, Heffner DK, Glenn GM, Patronas NJ, Pikus AT, et al. (1997) Endolymphatic sac tumors: a source of morbid hearing loss in von Hippel-Lindau disease. JAMA 277:1461-1466.

9. Megerian CA, Mc Kenna MJ, Nuss RC, Anthony J Maniglia, Robert G Ojemann, et al. (1995) Endolymphatic sac tumors: histopathologic confirmation, clinical characterization, and implication in von HippelLindau disease. Laryngoscope 105: 801-808.

10. Michal M, Tomas Vanecek, Radek Sima, Petr Mukensnabl, Ludmila Boudova, et al. (2004) Primary capillary hemangioblastoma of peripheral soft tissues. Am J Surg Pathol 28: 962-966.

11. Kempermann G, Neumann HPH, Volk B (1998) Endolymphatic sac tumours. Histopathology 33: 2-10.

ISSN: 2574-1241

DOI: $10.26717 /$ BJSTR.2020.31.005060

Charnsiri Segsarnviriya. Biomed J Sci \& Tech Res

(C) This work is licensed under Creative

Submission Link: https://biomedres.us/submit-manuscript.php
12. Pollak A, Bohmer A, Spycher M, Fisch U (1995) Are papillary adenomas endolymphatic sac tumours? Ann OtolRhinolLaryngo 104: 613-619.

13. Hassard AD, Boudreau SF, Cronn CC (1984) Adenoma of the endolymphatic sac. J Otolaryngol 13: 213-216.

14. Bambakidis NC, Rodrigue T, Megerian CA, Robert A Ratcheson (2005) Endolymphatic sac tumor metastatic to the spine. Journal of Neurosurgery 3: 68-70.

15. Michael L (2007) Tumors of the middle ear, in Diagnostic Histopathology of Tumor, Churchill livingstone, Elsevier, ( $3^{\text {rd }}$ Edn.)., 2: 1813-1820.

$\begin{array}{ll}\text { BIOMEDICAL } & \text { Assets of Publishing with us } \\ \text { RESEARCHES } & \text { - Global archiving of articles } \\ & \text { - Immediate, unrestricted online access } \\ & \text { - Rigorous Peer Review Process } \\ & \text { - Anttps://biomedres.us/ }\end{array}$

